HE Jiaxun, LU Taihong

\title{
Consumer-brand relationship in the context of Chinese culture: A theoretical construct and empirical study
}

\author{
(C) Higher Education Press and Springer-Verlag 2009
}

\begin{abstract}
Using the theory of indigenous interpersonal relationship and the metaphor of the brand-as-relationship-partner (BARP), this paper develops a theoretical construct of consumer-brand relationship in the Chinese context and proposes a brand relationship framework that consists of four basic types, namely "family member", "good friend", "cooperation partner", and "acquaintance". This paper also reports the findings of two studies that test the acceptability of the theoretical construct. Study 1 proves that the relationship metaphor is suitable for the appraisal of consumer-brand relationship in the Chinese context. Study 2 confirms that the brand relationship types and brand relationship quality have satisfactory concurrent validity.
\end{abstract}

Keywords consumer-brand relationship, brand relationship types, brand relationship quality, indigenous perspective

摘要 借用本土人际关系理论对中国消费者一品牌关系进行了理论建构, 认为 存在四种基本的品牌关系类型：“家人关系”、“好朋友关系”、“合作伙伴关系” 和“熟人关系”, 这四种类型可以揭示并描述品牌关系的差异。通过两个研究验 证了理论建构的合理性: 研究 1 初步证明了本土人际关系隐喻适用于中国消费 者一品牌关系的情境; 研究2进一步证明了品牌关系类型与品牌关系质量具有良

Translated and revised from Yingxiao Kexue Xuebao 营销科学学报 (Journal of Marketing Science), 2007, 3(3): 1-12

HE Jiaxun $(\bowtie)$

Center of Branding Science, School of Business, East China Normal University, Shanghai 200241, China

E-mail: jxhe@dbm.ecnu.edu.cn

LU Taihong

School of Business, Sun Yat-sen University, Guangzhou 510275, China

E-mail: mnslth@mail.sysu.edu.cn 
好的同时效度。

关键词 消费者一品牌关系, 品牌关系类型, 品牌关系质量, 本土化研究

\section{Introduction}

Over the past decade, western scholars have paid much attention to studying the consumer-brand relationship from the perspectives of relationship theory (e.g., Fournier, 1998; Muniz and O'Guinn, 2001; Aggarwal, 2004; Aggarwal and Law, 2005). Applying the relationship marketing theory to branding studies could provide enlightenment for consumer behavior study. It deepens the insights into the interaction between consumer and brand (Fournier, 1995), broadens the understanding of brand conception based on the traditional brand theories (such as brand attitude, brand satisfaction, brand loyalty and brand personality) (Fournier, 1994, 1998), and opens a new phase for the study of customer-based brand equity (He, 2006).

The core rationale of the consumer-brand relationship study is "brand-as-relationship-partner" (BARP) (Fournier, 1994, 1998; Aggarwal, 2004). All the marketing activities can be regarded as a series of behavior events which realize the brand trait inferences and brand personalities. These daily executed marketing mix decisions consists of a chain of acts representing brands. Thus, brand can be truly regarded as an active and contributing relationship partner (Fournier, 1998). Under this underlying premise and with the assistance of the interpersonal relationship theories in social psychology, including social cognition theory, symbolic interaction theory, Western researchers have made extensive contributions to consumer-brand relationship. The related research achievements enrich the research findings in interpersonal relationship, group psychology, and self consciousness (self schema).

However, so far, there have been few studies on the adaptability of the metaphor "brand-as-relationship-partner" to Chinese consumers in an undeveloped market. Furthermore, as the interpersonal relationship perspective can well relates "culture/society/history" with modern individuals (Yang, 2001a), consumer-relationship studies from the indigenous perspective in the context of Chinese culture are of high significance and need to be further developed.

This paper identifies basic types of Chinese consumer-brand relationship under the guidance of indigenous social psychology (interpersonal relationship theories). Meanwhile, through a correlation study of brand relationship quality, this paper builds a basic theoretical framework of the relationship-based 
perspective of brand equity in the context of Chinese culture.

\section{Literature review and theoretical background}

\subsection{Literature review}

According to the relationship perspective, brand equity stems from consumer-brand relationship (Fournier, 1994). In order to develop the construct of BARP and thus to potentially use "relationship metaphor" in the description of consumer-brand phenomenon, Fournier $(1994,1998)$ first showed through an exploratory study that some relative concepts and theories in interpersonal relationship can adapt to the construct-building of consumer-brand relationship, and she also concluded 15 types of consumer-brand relationships. These relationship types can fall into four categories: friendships, marriages, "dark-side" relationships, and temporally oriented relationships (Sweeney and Chew, 2000). Following the initiative work of Fournier, many scholars have conducted similar brand relationship (type) studies. From the perspective of consumers, studies covered women (Olsen, 1999) and children (Ji, 2002). From the perspective of brands, studies extended to the service sector (Sweeney and Chew, 2000) and the online world (Thorbjornsen et al., 2002). All of these studies suggest that the consumer-brand relationship types induced from the interpersonal relationship metaphor can be used to describe and distinguish the different brand attitudes of consumers and to make up the deficiencies of the traditional prevailing constructs such as brand loyalty (Fournier and Yao, 1997).

Based on the previous exploratory studies and according to the classical theories of social psychology, some researchers referred the basic relationship types in social relationship to study how different consumer-brand relationships influence consumers' brand attitudes. For example, Kaltcheva and Weitz (1999) used the construct of interpersonal relationship schema (mediation and reciprocity); Thomson and Johnson (2002) used the construct of "attachment style"; Aggarwal (2004) used the construct of "relationship norm". Aggarwal et al. concluded that, in the interaction between consumers and brands, compared with the brand action in accordance with the relationship norm, the ones against the norm get the worse evaluation from the consumers (Aggarwal, 2002, 2004); compared with exchange relationship norm, communal relationship norm leads the consumers to evaluate the brand attributes on a comparatively higher abstract level (Aggarwal and Law, 2005) and thus results in a higher degree of loss aversion (Aggarwal and Zhang, 2006). These results suggest that relationship type, as an antecedent variable, moderates consumers' reactions toward brand activities, processes to brand information and the effects of loss aversion, and 
thus proves the importance of building an appropriate brand relationship in management.

As above, we can conclude that under the Western background, the relationship patterns or types in the interpersonal relationship study can also be applied to the consumer-brand relationship field, which provides an extraordinary good opportunity for exploring the complicated and fascinating world of consumer-brand interaction (Aggarwal, 2004). However, it is worthwhile to point out that the two relationship types (exchange relationship and communal relationship) are directly borrowed from relevant studies in social psychology (Clark and Mills, 1993). Although they are the simplest dichotomy distinguishing the relationship types, they may have neglected more existing patterns.

\subsection{The Chinese indigenous research perspective}

Applying the classical social psychological theories to the marketing science research cannot avoid the social science problems that closely related to the local socio-cultural-historical factors. Meanwhile, as Western psychology studies mainly focus on individual characteristics, their findings are not necessarily suitable for the "social-oriented" Chinese people (Yang, 1998). Therefore, this paper chooses an indigenous research perspective, which means that the theories and methodology adopted are mainly derived from the researcher's own society (Zhai, 2001). This kind of indigenous study is an important orientation in the development of social science (Yang, 1998).

In the context of Chinese culture, the most forceful determinate element for social behavior is not the individual itself, but the relationship context beyond individuals (Ho et al., 1991). The overwhelming influence (i.e. relationship dominance) of interpersonal relationship reflects the social behavior pattern in Confucius culture, which forms a comparison with the Western individualism (Ho and Peng, 1998). This difference also affects the consumer-brand relationship in China. Hamilton and Lai (1989), Tse (1996) and Eckhardt and Houston (2001) has pointed out that, Chinese consumers regard brand (name) as an instrument to build social relationship, the fundamental meaning of brand to Chinese consumers is to reflect the ways of their interpersonal interaction and the ways they consider the society. Therefore, this basic interpersonal orientation of the Chinese people has already naturally affected their social motivations of consumer-brand relationship. As a result, the findings of studies in Chinese people's interpersonal relational orientation lay the theoretical foundation for revealing and expressing consumer-brand relationship. 


\subsection{Theoretical construct based on indigenous interpersonal relationship}

In Chinese, "guanxi" refers to interpersonal relationship (Alston, 1989; Arias, 1998; Su and Littlefield, 2001; Fan, 2002; Wong and Leung, 2001). It reflects a social norm of interdependence, which is typical for nations with culture of collectivism such as China (Hofstede, 2001). Most social psychologists define interpersonal relationship as the psychological distance and behavioral intention between individuals based on their personal affects (Yang, 1995).

An important practice in conceptualizing relationship is to classify interpersonal relationships (Ho, 1998). In the traditional interpersonal relationship studies in the context of Chinese culture, scholars put forward various classifications of relationship from different theoretical perspectives, such as Fei's (1985) "family members" and "outsiders", Hwang's (1988a, 1988b) affective, instrumental and mixed relationships, and Yang's (1992) family members, acquaintances, and strangers. Besides, Zhai (1993) promoted a basic model of Chinese interpersonal relationship consists of "yuan" (predestined relationship), "qing" (affection), and "lun" (ethics). In this model, "qing" interprets what interpersonal behavior is, "lun" indicates how to interpret interpersonal behavior, and "yuan" suggests why interpersonal behavior is thusly preceded. Therefore, the model could represent a system including value presetting, psychology and norms. Yang (2001b) commented that, from Zhai's (1993) framework, we could conclude that affection is the most important factor in the conceptualization of Chinese interpersonal relationship. She pointed out that Chinese culture is an affect-oriented culture, and this fact is reflected in any interpersonal interactions in which people always give their counterparts the basic "ren qing" (favor) (Yang, 2001c).

According to Yang (2001c), this kind of "ren qing" has a strong feeling of obligation and compulsion, and thus, when people express their feeling in the real life, there is a gap or separation between "qing" and "li" (etiquette). Sometimes we know that considering " $l i$ ", we should give someone "qing", but in fact there isn't any "qing" existing in our hearts. Therefore, she puts forward a bi-dimensional structure, "assumed affection" (obliged, regulated emotions, or "ren qing") and "real affection" (real, spontaneous emotions, or "gan qing"), to classify interpersonal relationships (Yang, 2001c) and to interpret the affective world of the Chinese people (Yang, 2001d), which is shown in Table 1. This construct has been proved by many empirical tests. Lau et al. (2005) also suggested that the affective elements in Chinese interpersonal relationships commonly contain an obligation characteristic. 
Table 1 The classification of interpersonal relationships based on the bi-dimensional structure of affect

Ren qing (assumed affection)

Source: Yang (2001c) and Yang (2001).

How shall we interpret the roles of "real affect" and "assumed affect" and the relationship between the two? Yang (1990) pointed out that on the one hand, these two kinds of affections would separately operate during the process of interpersonal interaction, but on the other hand, people could simultaneously have these two feeling towards one person and the relationship between these two feelings is not necessarily mutually exclusive or complementary. Though playing different roles in interpersonal interaction, two kinds of affections are equally important. "If there are no real affections when exchanging the assumed affections, it will be considered quite mendacious; if express the real affections without considering the assumed affections in a certain situation, it will be thought very rude" (Yang, 2001d). It is therefore not difficult to see that the proportion of the contents of "real affection" and "assumed affection" will influence the relationship quality, but the real quality of affection should be considered based on the balanced development of the two elements. Besides, the difference between "real affection" and "assumed affection" can be used to describe the nature distinction of the relationship patterns and the difference may also result in different relationship outcomes. If we say that "real affection" influences the strength of relationship, then, "assumed affection" tends to have more influence on the durability of relationship.

In this way, we can understand the difference between Chinese and Western interpersonal interactions. Compared with "affection", which is much emphasized by the Westerners, the Chinese attach more importance to "qing", an implicated obligation, and "ren qing", which is needed in their daily life (Hsu, 1971). Yang (2001c) states, "As the indigenous culture pays much attention to this norm, we can not only consider the spontaneous affections generated from 
experience like the Western scholars and therefore focus on intimacy in the research of interpersonal affection; we must consider more about the required and obliged affection". "Assumed affection" can also independently reflect the "differential order-pattern" in Chinese interpersonal relationships (Yang, 2001; Yang, 2001c), i.e. the more intimate the insider is with us, the higher "assumed affection" we will have, and the more isolated the outsider is with us, the lower "assumed affection" we will have. As shown in Table 1, we can see that at the lower relationship level, "assumed affection" has no influence, but with the development of the relationship, "assumed affection", like "real affection", becomes the element to improve and enhance (Path A and Path B) the relationship quality and finally helps it achieve the ideal state, though the relationship type of their middle state still has some different natures.

According to Table 1, affective elements can differentiate the quality and nature of relationship, and their constitutional difference clarifies four basic relationship types or levels. The most ideal relationship quality is that "assumed affection" and "real affection" merge with each other without any gap in between. The best situation is that both "assumed affection" and "real affection" are under the high relationship status of "insiders". On the contrary, the worst situation is that both are under the low relationship status, "market transaction relationship". Accordingly, adopting the common titles in daily life, this paper brings up four basic relationships, "family member relationship", "good friend relationship", "cooperative partner relationship" and "acquaintance relationship", to represent the four relationship types. In the types that contain both high "assumed affection" and high "real affection", the "family member relationship" is a typical example. In the types including high "real affection" and low "assumed affection", "good friend relationship" is a typical case, and "cooperative partner relationship" represents types including high "assumed affection" and low "real affection". In the types that have low "assumed affection" and low "real affection", "acquaintance relationship" is a typical instance.

This paper applies the interpersonal relationship classification to the brand relationship context, holding that the Chinese consumers' affection towards brands also contain "assumed affection" and "real affection". The former means consumers' uncontrollable positive emotional reactions, such as delight, happiness, and interest, toward the brand they like. The latter refers to the obliged and assumed affections generated by the consumers under the influence of cultural norms such as patriotism, family and tradition, and occasions and etiquettes. Therefore, there are also four basic types of consumer-brand relationships, namely "family member relationship", "good friend relationship", "cooperative partner relationship", and "acquaintance relationship". Can Chinese consumers use this metaphor to evaluate the differences of their relationships with brands? Are the titles of these four 
relationship types representative of the real relationships? Could these brand relationship types represent the differences in qualities of brand relationships and thus possess the basic functions to differentiate types? In the following sections, we will try to bring out solutions to these questions in two studies.

\section{Study 1: Exploration on the validity of indigenous interpersonal relationship's function of brand relationships differentiation}

\subsection{Research method and survey design}

The purpose of this research is to make a tentative exploration on whether the brand relationship types based on the metaphor of Chinese interpersonal relationship can efficiently differentiate brand relationships and whether the four relationship titles brought up in this paper can represent the relationship types. Under this research purpose, the authors, basing on the conceptual model of classifying interpersonal relationships according to the bi-dimensional structures of affections and referring the basic relationship titles in Chinese interpersonal relationship study (Yang, 2001; Yang, 2001c), list 16 interpersonal relationship forms (other forms are classified as "others"), which can be separately placed in the following situations with high or low real affection and assumed affection:

High real affection and high assumed affection: family members, couples, faithful pals, brothers and sisters, parents and close relatives;

Low real affection and high assumed affection: cooperative partners, distant relatives and benefactors;

High real affection and low assumed affection: good friends, lovers and intimate friends;

Low real affection and low assumed affection: acquaintances, general contacted people, common friends and transaction relationship.

The questionnaire requires the participant to choose the consumption goods brand that he or she is using in the present daily life and that first comes to his or her mind, to recall the actual useful years (because "relationship length" is the dependent variable), and eventually make a judgment and choice about the corresponding relationship forms of his or her own evaluation about his or her relationship with this specific brand (independent variable).

Seeing from the concept of "differential order-pattern", the 16 interpersonal relationship forms listed in this study have covered the continuous closeness 
sequence from immediate family members to strangers, and when applying them to the consumer-brand relationship context, they should represent the general differences in various relationship qualities. On the other hand, as relationship length (years of usage) is an index to measure relationship quality (Storbacka, Strandvik and Grönroos, 1994; Heide, 2003), theoretically they should have correlation with each other. If seen from the brand relationship length, there are significant differences among the four relationship types, this would provide a positive evidence for the validity of indigenous interpersonal relationship's applying to the consumer-brand relationship area. Besides, if the result does show that domestic and foreign brands vary in different relationship forms and types, then it can provide evidences for the applicability of relationship perspective to brand equity evaluation.

\subsection{Data processing and results}

This research adopts the method of questionnaire with residents living and working in Shanghai as participants. The sample was collected from the classes of continual education programs at East China Normal University, Shanghai, China. 600 questionnaires were distributed and in total 584 valid ones (i.e. brand-consuming cases) were collected, which represents a 97\% return rate. Among the investigated brands, 66\% were foreign brands and $34 \%$ were domestic brands. The average consumption duration was 4.97 years (S.D. $=4.23$ ). Among the interviewees, $51 \%$ were males and $49 \%$ females (with 10 missing values). Their ages ranged from 19 to 43 with an average age of $26.3($ S.D. $=4.69)$ and the interviewees over the age of 25 took up $47 \%$ of the total participants. The questionnaire data were processed with SPSS 13.0 software. This investigation was conducted in March and April in 2005.

ANOVA test shows that either for the 17 relationship forms $(F=2.143, d . f .=16$, $p<0.01)$ or for the 4 relationship types $(F=3.214$, d.f. $=3, p<0.05)$ (exclude the relationship form "others", so there are 574 valid cases), as to consumption duration, there are significant differences among the forms or types. Specifically, for the relationship types with both high real affection and assumed affection, the average brand consumption duration is 5.92 years (S.D. $=4.65$ ), for the relationship types with both low real affection and assumed affection, the average consumption duration is 4.41 years (S.D.=4.98), and for the ones with low real affection and high assumed affection and the ones with high real affection and low assumed affection, the average brand consumption durations are 4.82 years (S.D.=3.16) and 4.81 years (S.D.=3.83), separately (see Fig. 1). Therefore, we can conclude that the higher the brand relationship quality, the longer its consumption years (relationship length). 


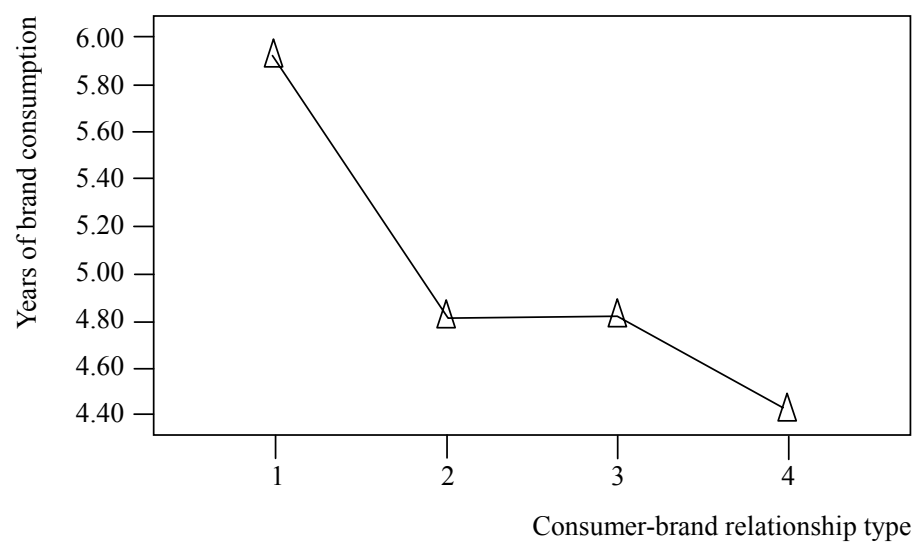

$1=$ High real affection and high assumed affection
$2=$ Low real affection and high assumed affection
$3=$ High real affection and low assumed affection
$4=$ Low real affection and low assumed affection

Fig. 1 Brand relationship length of different relationship types (consumption duration)

Among the 17 relationship forms, the most frequently selected four are good friends, cooperative partners, family members, and acquaintances, which account for $54 \%$ of all the cases (see Table 2). These four relationship forms are directly correspondent to the four relationship types in the conceptual model constructed by Yang (2001c) and Yang (2001) (see Table 1). Thus, it can be concluded that these four relationship forms are the typical titles representing the four relationship quality types, which in accordance with the theoretical construction of this paper. In Study 2, we will define these four relationship forms and use them to measure the concurrent validity of brand relationship quality.

Using chi-square test, we find that there are significant differences in the 17 relationship forms between domestic brands and foreign ones $\left(\chi^{2}=31.88, d . f .=16\right.$, $p<0.05)$. In addition, at the significance level of 0.1 , the four relationship types are also significantly different $\left(\chi^{2}=7.5, d . f .=3, p<0.1\right)$. In Type One (high real affection and high assumed affection), the percentage of domestic brands (26.9\%) is higher than that of the foreign brands (23.6\%); but in Type Four (low real affection and low assumed affection), the percentage of domestic brands (27.4\%) also surpasses that of the foreign brands (20.7\%). In addition, though in Type Two (low real affection and high assumed affection), the percentage of domestic brands $(18.3 \%)$ is close to that of foreign brands (17.5\%), in Type Three (high real affection and low assumed affection), the percentage of domestic brands $(27.4 \%)$ is much lower than that of the foreign brands (38.2\%). 
Table 2 Four most frequently selected relationship forms and corresponding brand consumption years

\begin{tabular}{|c|c|c|c|c|c|c|c|c|}
\hline & \multirow[t]{2}{*}{ Frequency } & \multirow[t]{2}{*}{ Mean } & \multirow[t]{2}{*}{ S.D. } & \multirow{2}{*}{$\begin{array}{l}\text { Std. } \\
\text { error }\end{array}$} & \multicolumn{2}{|c|}{$\begin{array}{l}95 \% \text { Confidence } \\
\text { interval for mean }\end{array}$} & \multirow[t]{2}{*}{ Minimum } & \multirow[t]{2}{*}{ Maximum } \\
\hline & & & & & $\begin{array}{l}\text { Lower } \\
\text { bound }\end{array}$ & $\begin{array}{l}\text { Upper } \\
\text { bound }\end{array}$ & & \\
\hline Good friends & 121 & 5.28 & 4.07 & 0.37 & 4.55 & 6.02 & 0.30 & 20.00 \\
\hline $\begin{array}{l}\text { Cooperative } \\
\text { partners }\end{array}$ & 88 & 4.86 & 3.03 & 0.32 & 4.22 & 5.51 & 1.00 & 15.00 \\
\hline $\begin{array}{l}\text { Family } \\
\text { members }\end{array}$ & 51 & 6.77 & 5.20 & 0.73 & 5.31 & 8.23 & 1.00 & 28.00 \\
\hline Acquaintances & 48 & 4.84 & 5.51 & 0.80 & 3.24 & 6.44 & 0.50 & 35.00 \\
\hline
\end{tabular}

Note: $F=2.486$, d.f. $=3, p<0.1$.

\subsection{Explanation and preliminary conclusions}

The above results indicate that the classification and theories of Chinese indigenous interpersonal relationship can be applied to the consumer-brand relationship study and could make valid differentiation of brand relationship qualities. There are four useable typical common relationship forms, namely family member relationship, good friend relationship, cooperative partner relationship and acquaintance relationship, which successively represent the four relationship types of Yang (2001c) from high to low. The present result shows that when real affection and assumed affection are both high, the brand relationship is likely to be maintained for a longer time. The four brand relationship types show the differences between domestic brands and foreign brands, and the most marked characteristic is that the indigenous companies' brand-building model commonly lacks the cultivation of "real affection". Compared with the foreign brands, the domestic brands tend to build a more "family member" like relationship, which reflects their close relationship with the local consumers.

\section{Study 2: Correlation between brand relationship type and brand relationship quality}

\subsection{Research method and survey design}

Fournier (1994) held that the construct of brand relationship quality can be used to distinguish brand relationship types. If so, are the four relationship types in the context of Chinese culture concluded from the above study able to represent the basic differences of brand qualities? In other words, can the ingredients of brand relationship quality explain the differences among brand relationship types? In order to answer these questions, we will test the significant differences among 
the brand relationship types with the indigenous Chinese Consumer Brand Relationship Quality (CBRQ) Scale (He, 2006).

We describe and define the connotation of the four brand relationship types in order to enable the participants to compare and evaluate them. Likert 5 points scale is used. CBRQ scale is composed of 25 measured items within six facets, "social value expression", "trust", "interdependence", "real and assumed affections", "commitment", and "self-concept connection", which has a good construct validity (RMSEA $=0.076, \mathrm{NNFI}=0.91, \mathrm{CFI}=0.92$ ). A 5-point Likert scale is adopted to measure each variable.

This research regards the differentiating of the two situations, high level relationship and low level relationship, as a fundamental premise. In their relationship marketing studies, Dwyer, Schurr and Oh (1987) pointed out that there is a continuum from transaction to relationship orientation and consumers have different relationship orientations. Therefore, customers do not require the same relationship status. In order to better represent this relationship marketing thought, we should focus on different relationship levels to study the corresponding relationship function mechanism, and thus can provide a more valid evaluation for the consumer market segmentation. Therefore, from the viewpoint of individual consumers, this study divides the consumer brand relationships into two basic situations: high level brand relationship (intimate brand relationship) and low level brand relationship (ordinary brand relationship). Here, the difference between "high level" and "low level" is similar to the concepts of "intimate" relationship and "ordinary" relationship in interpersonal relationship. Meanwhile, it could also represent the difference between "important relationship" and "common relationship". The authors have tested each participant with two brands: The first brand is "the most intimated brand" for the consumer (high level relationship situation), and it should play an important role in the participant's life and can arouse the participant's intense emotions. As the participant has been using this brand for a long time, he/she is familiar enough with it and can discuss it in details. The second brand is the one that the participant feel not very intimated with. Though he/she has a positive emotion about this brand, it is obviously inferior to "the most intimated brands". The participant may have been using this brand for a short time or is unlikely to think much about it (low level relationship situation).

This investigation, carried out in Shanghai in October and November in 2005, collects data by the way of questionnaire and regards the residents living and working in shanghai as subjects. The study uses convenient sampling method but ensures that the distribution of samples covers an extensive scope (in age, education and income) and that it can focus on the important brand consumption groups (young and middle-aged consumers with ages from 26 to 45 taking up 
$55.5 \%$ of the whole sample). 400 copies of questionnaire were distributed through several adult education programs (MBA, graduate course class) and undergraduate programs which taught by the first author at East China Normal University to reach themselves and their parents or kinships. 380 valid ones were returned which represents a $95 \%$ return rate. This kind of non-probability sampling method could also be found in many branding literature (e.g., Fournier, 1994; Netemeyer et al., 2004), and it is different with the convenient sampling method in which only the undergraduate students participate (e.g., Yoo and Donthu, 2001). On the choice of products and brands to be tested, the authors have looked up the consumption expenditures of Shanghai urban households and durable consumer goods owned by Shanghai urban households from Chinese Statistics Yearbook 2005, referred to 2004-2005 IMI Consumer Behavior and Life Types Yearbook to find the brands with higher market share in Shanghai market, and finally determined 34 categories and 80 brands (48 foreign and 32 domestic brands) as sample brands that were suitable for Shanghai market research.

\subsection{Result 1: Correlations between CBRQ facets and brand relationship types}

The first step is to examine correlations of the four relationship types (Table 3). Under the high level relationship situation, family member relationship is significantly correlated with good friend relationship and cooperative partner relationship. However, cooperative partner relationship and family member relationship have significant negative correlation. These results show that under high level relationship context, consumers believe that "cooperative partner relationship" is more likely to be a low quality relationship type.

Table 3 Correlations between the four brand relationship types

\begin{tabular}{lcccc}
\hline \multicolumn{1}{c}{ Variable } & Family member & Good friend & Cooperative partner & Acquaintance \\
\cline { 2 - 5 } & \multicolumn{5}{c}{ High level relationship situation } \\
\hline Family member & 1.00 & 1.00 & \\
Good friend & $0.330^{* *}$ & 0.075 & 1.00 & 1.00 \\
Cooperative partner & $-0.155^{* *}$ & -0.047 & $0.356^{* *}$ & \\
Acquaintance & -0.094 & Low level relationship situation & \\
\hline \multicolumn{5}{c}{1.00} \\
Family member & 1.00 & $0.303^{* *}$ & 1.00 & 1.00 \\
Good friend & $0.464^{* *}$ & $0.134^{* *}$ & $0.256^{* *}$ & \\
Cooperative partner & 0.044 & -0.069 & & \\
Acquaintance & &
\end{tabular}

Note: ${ }^{* *}$ means that the correlation is significant at the 0.01 level (2-tailed). 
Under the low level relationship situation, family member relationship and good friend relationship as well as cooperative partner relationship and acquaintance relationship have significant correlation. Good friend relationship is also significantly correlated with acquaintance relationship and cooperative partner relationship. This result suggests that under low level relationship context, consumers consider cooperative partner relationship as a "moderate" quality relationship type while acquaintance relationship is also a type expressive of relationship quality.

The following steps are used to test the correlation between CBRQ facets and the brand relationship types (Table 4). We can see that under the high level relationship situation, though both family member relationship and good friend relationship have significant correlations with the six facets of CBRQ, the correlations of family relationship and the six facets of CBRQ are higher than that of good friend relationship. Under the low level relationship situation, family member relationship and good friend relationship both have significant correlation with the six facets of CBRQ, but the correlations of good friend relationship and the six facets of CBRQ is higher. To a certain degree, this result proves that in relationship quality, family member relationship is a type with higher quality comparing with good friend relationship.

Table 4 Correlations between CBRQ facets and brand relationship types

\begin{tabular}{|c|c|c|c|c|c|c|c|}
\hline $\begin{array}{l}\text { Facets of the } \\
\text { CBRQ scale }\end{array}$ & $\begin{array}{l}\text { Social value } \\
\text { expression }\end{array}$ & Trust & Interdependenc & $\begin{array}{l}\text { Real and } \\
\text { assumed } \\
\text { affections }\end{array}$ & Commitment & $\begin{array}{l}\text { Self-concept } \\
\text { connection }\end{array}$ & CBRQ \\
\hline \multicolumn{8}{|c|}{ High level relationship situation, Pearson Correlation } \\
\hline $\begin{array}{l}\text { Family } \\
\text { member }\end{array}$ & $0.232^{* *}$ & $0.262^{* *}$ & $0.338^{* *}$ & $0.332^{* *}$ & $0.302^{* *}$ & $0.270^{* *}$ & $0.393^{* *}$ \\
\hline Good friend & $0.172^{* *}$ & $0.151^{* *}$ & $0.171^{* *}$ & $0.258^{* *}$ & $0.122^{*}$ & $0.201^{* *}$ & $0.247^{* *}$ \\
\hline $\begin{array}{l}\text { Cooperative } \\
\text { partner }\end{array}$ & 0.026 & -0.059 & -0.003 & $-0.106^{*}$ & $-0.101^{*}$ & -0.016 & -0.056 \\
\hline Acquaintance & -0.076 & $-0.208^{* *}$ & $-0.156^{* *}$ & $-0.176^{* *}$ & $-0.146^{* *}$ & $-0.115^{*}$ & $-0.174^{* *}$ \\
\hline \multicolumn{8}{|c|}{ Low level relationship situation, Pearson Correlation } \\
\hline $\begin{array}{l}\text { Family } \\
\text { member }\end{array}$ & $0.275^{* *}$ & $0.268^{* *}$ & $0.464^{* *}$ & $0.449^{* *}$ & $0.384^{* *}$ & $0.310^{* *}$ & $0.437^{* *}$ \\
\hline Good friend & $0.431^{* *}$ & $0.517^{* *}$ & $0.419^{* *}$ & $0.562^{* *}$ & $0.417^{* *}$ & $0.487^{* *}$ & $0.573^{* *}$ \\
\hline $\begin{array}{l}\text { Cooperative } \\
\text { partner }\end{array}$ & $0.273^{* *}$ & $0.402^{* *}$ & $0.234^{* *}$ & $0.302^{* *}$ & $0.272^{* *}$ & $0.319^{* *}$ & $0.363^{* *}$ \\
\hline Acquaintance & 0.085 & 0.109 & -0.043 & 0.091 & 0.013 & $0.114^{*}$ & 0.074 \\
\hline
\end{tabular}

Under the high level relationship situation, cooperative partner relationship has no significant correlation with most of the six facets of CBRQ while 
acquaintance relationship has significant negative correlation with most of them. That is to say, for the high level relationship, acquaintance relationship is evidently a low quality relationship that has a reverse predictive effect. Under the low level relationship situation, cooperative partner relationship has significant correlation with the six facets of CBRQ while acquaintance relationship almost has no significant correlation with them. In other words, under the low level relationship, cooperative partner relationship has predictive effect while acquaintance relationship has no predictive effect.

Overall, we can conclude that brand relationship types have significant correlations with the six facets in CBRQ, which indicates that brand relationship types could represent the corresponding brand relationship quality.

\subsection{Result 2: Difference analysis of brand relationship types in CBRQ}

We have tested the correlation between brand relationship types and the facets in CBRQ above, but could the finding prove that the evaluation difference in relationship types is noticeably reflected on the CBRQ facets? We will use Univariate and MANOVA tests to figure out the issue.

Before conducting variance analysis, we first examine the normal distribution, the homogeneity of variance and the independency of each sample. The examination adopts Pillai Trace Method, which could provide the most stable results. Table 5 and Table 6 separately show the descriptive data under high level relationship situation and low level relationship situation, as well as the results in univariate and MANOVA tests.

From the results in Univariate tests, we can see that in the high level relationship situation, family member relationship $(p<0.001)$, good friend relationship $(p<0.05)$ and acquaintance relationship $(p<0.01)$ have statistic significance for the overall CBRQ evaluation, but cooperative partner relationship proves to be statistically insignificance $(p>0.1)$. Referring to the distribution of descriptive data, we can perceive that the high evaluation in the types of "family member relationship" and "good friend relationship" also has exists in the overall CBRQ evaluation.

Under the low relationship situation, the first three relationship types $(p<0.001)$ are significant in statistics for the overall CBRQ evaluation. That is to say, if consumers value high of "family member relationship", "good friend relationship" and "cooperative partner relationship", their evaluation of brand relationship quality is high as well.

As above, we can see that no matter the relationship context is of high level or low level, various relationship types have significant differences in the overall CBRQ evaluation. 
Table 5 Variance analysis of four brand relationship types (high level relationship situation)

\begin{tabular}{|c|c|c|c|c|c|c|c|c|}
\hline \multirow{2}{*}{$\begin{array}{l}\text { Value of } \\
\text { relationship type }\end{array}$} & \multicolumn{2}{|c|}{ Family member } & \multicolumn{2}{|c|}{ Good friend } & \multicolumn{2}{|c|}{ Cooperative partner } & \multicolumn{2}{|c|}{ Acquaintance } \\
\hline & Mean & S.D. & Mean & S.D. & Mean & S.D. & Mean & S.D. \\
\hline 1 & 3.420 & 0.440 & 3.663 & 0.692 & 3.909 & 0.598 & 4.117 & 0.477 \\
\hline 2 & 3.661 & 0.574 & 3.467 & 0.509 & 3.954 & 0.522 & 3.977 & 0.484 \\
\hline 3 & 3.887 & 0.484 & 3.849 & 0.565 & 3.937 & 0.469 & 3.761 & 0.466 \\
\hline 4 & 3.957 & 0.453 & 3.903 & 0.548 & 3.913 & 0.575 & 3.789 & 0.609 \\
\hline 5 & 4.228 & 0.489 & 4.034 & 0.448 & 3.851 & 0.494 & 3.897 & 0.491 \\
\hline \multicolumn{9}{|c|}{ Univariate analysis (Model $F$-value $=6.512, P=0.000$, Adjusted $R^{2}=0.191$ ) } \\
\hline$F$-value & \multicolumn{2}{|c|}{12.280} & \multicolumn{2}{|c|}{2.457} & \multicolumn{2}{|c|}{1.002} & \multicolumn{2}{|c|}{4.193} \\
\hline Sig. & \multicolumn{2}{|c|}{0.000} & \multicolumn{2}{|c|}{0.045} & \multicolumn{2}{|c|}{0.406} & \multicolumn{2}{|c|}{0.002} \\
\hline \multicolumn{9}{|l|}{ Multivariate analysis } \\
\hline Pillai's Trace & \multicolumn{2}{|c|}{0.166} & \multicolumn{2}{|c|}{0.092} & \multicolumn{2}{|c|}{0.071} & \multicolumn{2}{|c|}{0.094} \\
\hline$F$-value & \multicolumn{2}{|c|}{2.555} & \multicolumn{2}{|c|}{1.399} & \multicolumn{2}{|c|}{1.071} & \multicolumn{2}{|c|}{1.424} \\
\hline Sig. & \multicolumn{2}{|c|}{0.000} & \multicolumn{2}{|c|}{0.095} & \multicolumn{2}{|c|}{0.366} & \multicolumn{2}{|c|}{0.084} \\
\hline
\end{tabular}

Table 6 Variance analysis of four brand relationship types (low level relationship situation)

\begin{tabular}{|c|c|c|c|c|c|c|c|c|}
\hline \multirow{2}{*}{$\begin{array}{l}\text { Value of } \\
\text { relationship type }\end{array}$} & \multicolumn{2}{|c|}{ Family member } & \multicolumn{2}{|c|}{ Good friend } & \multicolumn{2}{|c|}{ Cooperative artner } & \multicolumn{2}{|c|}{ Acquaintance } \\
\hline & Mean & S.D. & Mean & S.D. & Mean & S.D. & Mean & S.D. \\
\hline 1 & 2.644 & 0.757 & 2.201 & 0.748 & 2.255 & 0.932 & 2.960 & 1.125 \\
\hline 2 & 2.983 & 0.739 & 2.657 & 0.707 & 2.841 & 0.775 & 2.933 & 0.817 \\
\hline 3 & 3.099 & 0.648 & 3.020 & 0.654 & 3.015 & 0.734 & 3.114 & 0.717 \\
\hline 4 & 3.508 & 0.567 & 3.375 & 0.572 & 3.104 & 0.677 & 3.095 & 0.697 \\
\hline 5 & 3.862 & 0.656 & 3.693 & 0.563 & 3.515 & 0.634 & 3.061 & 0.662 \\
\hline \multicolumn{9}{|c|}{ Univariate analysis $\left(\right.$ Model $F$-value $=18.100, P=0.000$, Adjusted $\left.R^{2}=0.419\right)$} \\
\hline$F$-value & \multicolumn{2}{|c|}{10.435} & \multicolumn{2}{|c|}{16.565} & \multicolumn{2}{|c|}{10.043} & \multicolumn{2}{|c|}{0.993} \\
\hline Sig. & \multicolumn{2}{|c|}{0.000} & \multicolumn{2}{|c|}{0.000} & \multicolumn{2}{|c|}{0.000} & \multicolumn{2}{|c|}{0.411} \\
\hline \multicolumn{9}{|c|}{ Multivariate analysis } \\
\hline Pillai’s Trace & \multicolumn{2}{|c|}{0.227} & \multicolumn{2}{|c|}{0.237} & \multicolumn{2}{|c|}{0.170} & \multicolumn{2}{|c|}{0.073} \\
\hline$F$-value & \multicolumn{2}{|c|}{3.617} & \multicolumn{2}{|c|}{3.784} & \multicolumn{2}{|c|}{2.676} & \multicolumn{2}{|c|}{1.116} \\
\hline Sig. & \multicolumn{2}{|c|}{0.000} & \multicolumn{2}{|c|}{0.000} & \multicolumn{2}{|c|}{0.000} & \multicolumn{2}{|c|}{0.317} \\
\hline
\end{tabular}

MANOVA analysis results are presented in Table 5 and 6 to demonstrate if different relationship types have significant difference in the evaluation of each facet of CBRQ. The result shows that under the high level relationship situation, only "family member relationship" $(p<0.001)$ is significantly different, while under the low level relationship situation, except for "acquaintance relationship", all the first three relationship types $(p<0.001)$ are significant. In other words, under the high level relationship situation, the evaluations of "family member relationship" have significant difference in the evaluation of each facet of CBRQ, and under the low level relationship situation, "family member relationship", "good friend relationship" and "cooperative partner relationship" have significant differences in the evaluation of each facet of CBRQ. 


\section{Conclusion}

This paper constructs a basic framework of Chinese consumer-brand relationship by referring to theoretical results in indigenous interpersonal relationship studies. Differentiating affection into two dimensions, "real affection" and "assumed affection", this framework brings out the four basic brand relationship types, namely family member relationship, good friend relationship, cooperative partner relationship and acquaintance relationship. These four basic brand relationship types in Chinese culture context could be used to distinguish various relationships between Chinese consumers and brands, which is an important contribution of this paper. This basic framework can also provide fundamental diagnosis and management guideline for companies to improve their customer-oriented brand management.

This paper also suggests that the indigenous interpersonal relationship theory is applicable to the study of Chinese consumer brand relationship. This fact proves good prospect for branding theoretical study in the context of Chinese culture. However, so far, there are few studies using a real emic approach. On the basic problems of brand affections, our indigenous study results have significant differences from Western theories. Keller $(2001,2003)$ defines brand affection as "customer's emotional response and reaction toward brands" in his "pyramid model of customer-based brand equity", which includes brand feeling as module. In addition, in Fournier's $(1994,1998)$ BRQ model, there is a facet called "love and passion". Both of the above studies point out the consumer's affective elements towards brands, but neither of them refers to "the assumed affection". However, in the Chinese consumers' affective world, there are "ren qing", the assumed affection, and "gan qing", the real affection (Yang, 2001c). In Chinese consumer brand relationship, these two affective elements coexist at the same time and they can not only separate from each other but can also mix together (He, 2006). That is to say, in the context of Chinese culture, the studies on brand affections should take into account the "assumed affection", which is beyond pure intimate affections. These results indicate that the brand theories brought in form the developed Western countries are not entirely suitable for developing countries. On the other hand, research results from developing countries could be good complementary for the classical theories generated in mature market backgrounds.

In consumer-brand relationship field, studies on brand relationship types are of great importance (Lu and Zhou, 2003), and the recognition of brand relationship forms or types is not the ultimate purpose. The contribution of this paper is that it brings out a small number of more complicated relationship types to describe relationship situations within two dimensions and four quadrants. Compared with 
the two types put forward by Clark and Mills (1993), the four relationship types deducted in this paper each contains elements of "communal relationship" and "exchange relationship". For example, family member relationship is generally a communal relationship while good friend relationship is mainly an exchange relationship with a certain part of communal relationship in it. Compared with hypothesized relationship experiments, deduction in this paper is more effective for future actual condition studies.

This paper indicates that brand relationship types could imply the brand relationship quality differences and prove the reliability of the four-quadrant method in this area. Based on the four relationship types, future studies can proceed to explore how their differences in nature influence consumers' perception, attitude, and behavior, and what kinds of marketing implications these differences can offer to brand management.

Acknowledgements This work is supported by the National Natural Science Foundation of China (No.70772107) and Program for New Century Excellent Talents in University (NCET-08-0198).

\section{References}

Aggarwal P (2004). The effects of brand relationship norms on consumer attitudes and behavior. Journal of Consumer Research, 31(June): 87-101

Alston J (1989). Wa, Guanxi, and Inwa: Managerial principles in Japan, China, and Korea. Business Horizon, (March): 26-31

Ambler T, Bhattacharya C B, Edell J, Keller K L, Lemon K N, Mittal V (2002). Relating brand and customer perspectives on marketing management. Journal of Service Research, 5(1): $13-25$

Arias J T G (1998). A relationship marketing approach to guanxi. European Journal of Marketing, 32(1/2): 145-156

Eckhardt G M, Houston M J (2001). Cultural paradoxes reflected in brand meaning: McDonald's in Shanghai, China. Journal of International Marketing, 10(2): 68-82

Fan Y (2002). Questioning guanxi: Definition, classification and implications. International Business Review, 11: 543-561

Fournier S (1994). A consumer-brand relationship framework for strategic brand management. Unpublished doctoral dissertation, University of Florida

Fournier S (1995). Toward the development of relationship theory at the level of the product and brand. Advances in Consumer Research, 22: 661-662

Fournier S (1998). Consumers and their brands: Developing relationship theory in consumer research. Journal of Consumer Research, 24(March): 343-373

Fournier S (2000). Dimensioning brand relationships using brand relationship quality. Paper presented at the Association for Consumer Research annual conference, Salt Lake City, UT, October

Grönroos C (1991). The marketing strategy continuum: Toward a marketing concept for the 
1990s. Management Decision, 29(1): 7-13

Grönroos C (1994). From marketing mix to relationship marketing. Management Decision, 32(2): 4-19

Hamilton G, Lai C (1989). Consumerism without capitalism: Consumption and brand names in late imperial China. In: Henry Rutz and Benjamin Orlove (eds.), The Social Economy of Consumption: Monographs in Economic Anthropology, No.6. Lanham, MD: University Press of America, 253-279

Ho D Y F (1998). Interpersonal relationships and relationship dominance: An analysis based on methodological relationalism. Asian Journal of Social Psychology, 1: 1-16

Hofstede G (2001). Culture's Consequence: Comparing Values, Behaviors, Institutions, and Organizations Across Nations (2nd edition). Thousand Oaks: Sage Publications

Hsu F L K (1971). Eros, affect, and Pao. In: Hsu F L K (ed.), Kinship and Culture. Chicago: University of Chicago Press

Hsu F L K (1985). The self in cross-cultural perspective. In: Marsella A J, DeVos G, Hsu F L K (eds.), Culture and Self: Asia and Western Perspectives. New York: Tavistock, 24-55

Jeffrey H S (1998). A multidimensional conceptualization of consumer brand relationships: The differential impact of relationship dimensions on evaluative relationship outcomes. Unpublished doctoral dissertation, University of Colorado

Ji M F (2002). Children's relationships with brands: 'True love'or 'one-night' stand? Psychology \& Marketing, 19(April): 369-387

Kates S M (2000). Out of the closet and out on the street! Gay men and their brand relationships. Psychology \& Marketing, 17(June): 493-513

Keller K L (2001). Building customer-based brand equity. Marketing Management, 10(July-August): 14-18

Keller K L (2003). Strategic Brand Management: Building, Measuring, and Managing Brand Equity $\left(2^{\text {nd }}\right.$ Edition $)$. Pearson Education

Muniz Jr. A M Jr., O’Guinn T C (2001). Brand community. Journal of Consumer Research, 27(March): 412-432

Netemeyer R G, Krishnan B, Pullig C, Wang G, Yagci M, Dean D, Ricks J, Wirth F (2004). Developing and validating measures of facets of customer-based brand equity. Journal of Business Research, 57: 209-224

Olsen B (1999). Exploring women's brand relationships and enduring themes at mid-life. Advances in Consumer Research, 26: 615-620

Roth M S (1995). The effects of culture and socioeconomics on the performance of global brand image strategies. Journal of Marketing Research, 17(May): 163-175

Su C T, Littlefield J E (2001). Entering guanxi: A business ethical dilemma in mainland China? Journal of Business Ethics, 33: 199-210

Sun T, Horn M, Merritt D (2004). Values and lifestyles of individualists and collectivists: A study on Chinese, Japanese, British and US consumers. Journal of Consumer Marketing, 21(5): 318-331

Sweeney J C, Macy C (2000). Consumer-brand relationships: An exploratory study in the services context. Australia-New Zealand Marketing Academy (ANZMAC) Conference, $11^{\text {st }}$ November $-1^{\text {st }}$ December, Gold Coast, Australia

Thomson M, Johnson A R (2002). Investigating the role of attachment dimensions as predictors of satisfaction in consumer-brand relationships. Advances in Consumer Research, 29: 42

Thorbjornsen H, Supphellen M, Nysveen H, Pederson P E (2002). Building brand relationships online: A comparison of two interactive applications. Journal of Interactive Marketing, 16(3): 
$17-34$

Tse D (1996). Understanding Chinese people as consumers: Past findings and future propositions. In: The Handbook of Chinese Psychology, Michael Bond (ed.). Hong Kong: Oxford University Press, 352-363

Velitchka K, Weitz B (1999). The effects of brand-consumer relationships upon consumers' attributions and reactions. Advances in Consumer Research, 26: 455-462

Wong Y H, Leung T K P (2001). Guanxi: Relationship Marketing in a Chinese Context. New York: International Business Press.

Yang C F (1990). Conformity and defiance on tiananmen square: A social psychological perspective. In: Culture and Politics in China: An Anatomy of Tiananmen Square, Li P, Mark S, Li M H (eds.). New Brunswick, NJ: Transaction Publishers, 203-232

Yoo B, Donthu N (2001). Developing and validating a multidimensional consumer-based brand equity scale. Journal of Business Research, 52: 1-14

费孝通 (Fei Xiaotong) (1985). 乡土中国 (Native China). 北京: 三联书店

何佳讯 (He Jiaxun) (2006). 品牌关系质本土化模型的建立与验证 (Brand relationship quality: The establishment and validation of an indigenous model in China). 华东师范大学学报 (哲 学社会科学版), 38(3): 100-106

何友晖, 陈淑娟, 赵志裕 (He Youhui, Chen Shujuan, Zhao Zhiyu) (1991). 关系取向: 为中国社 会心理方法论求答案 (Relationship orientation: Seek for answers to China social psychology methodology). In: Yang K S and Hwang K K, Chinese Psychology and Behavior. 台北: 桂冠 图书股份有限公司, 49-66

何友晖, 彭泗清 (He Youhui, Peng Siqing)(1998). 方法论的关系论及其在中西文化中的应用 (Relationalism of methodology and its application in Chinese and Western Cultures). 社会学 研究, (5): 34-43

黄光国 (Huang Guangguo ) (1988a). 中国人的人情与关系 (The Favor and Guanxi of the Chinese). 台北：远流出版事业股份有限公司

黄光国 (Huang Guangguo) (1988b). 人情与面子: 中国人的权力游戏 (Favor and Face: the Power Game of the Chinese). 台北：远流出版事业股份有限公司, 289-318

刘嘉庆, 区永东, 吕晓薇 (Liu Jiaqing, Qu Yongdong, Lü Xiaowei) (2005). 华人人际关系的概念 化一一针对中国香港地区大学生的实证研究 (The conceptualization of Chinese guanxi of Hong Kong university students by using multi-dimensional scaling: An empirical approach). 心理学报, 37(1): 122-125

卢泰宏, 周志民 (Lu Taihong, Zhou Zhimin) (2003). 基于品牌关系的品牌理论: 研究模型及展望 (Branding theory based on band relationship: A research model and prospects). 商业经济与 管理, (2): 4-9

杨国枢 (Yang Guoshu) (1988). 台湾社会的发展：困境与超越 (Social science development in Taiwan: Difficulties and transcendence. In: Academic Exchange Committee of Philosophy Chinese Academy of Social Science, The Call of Chinese Humanism: The Collected works of the Academic Seminar on Developing Traditional Chinese Cultures). 台湾: 九洲图书出版 社

杨国枢 (Yang Guoshu) (1993). 中国人的社会取向: 社会互动的观点 (Social orientation of the Chinese: Perspective on social interactions. In: Yang K S and Yu Anbang, Chinese Psychology and Behavior-Conceptions and Methods). 台北: 桂冠图书公司, 87-142

杨宜音 (Yang Yiyin) (1995). 试析人际关系及其分类——兼与黄光国先生商榷 (A tentative analysis of interpersonal relationship and its classification-And a discussion with Hwang $\mathrm{K}$ K). 社会学研究, (5): 18-23

杨宜音 (Yang Yiyin) (2001). “自己人”: 一项有关中国人关系分类的研究个案研究 (“Insiders”: A special case study on the classificaiton of relationships of the Chinese). In: 中国人的人际关 
系、情感与信任一几个人际交往的观点 (The Interpersonal Relationships, Affection and Trust of the Chinese-A Perspective on Interpersonal Relationship). 台北: 远流出版事业股份 有限公司, 131-157

杨中芳 (Yang Zhongfang) (2001a). 序言 (Prelude). In: 中国人的人际关系、情感与信任一一几 个人际交往的观点 (The Interpersonal Relationships, Affection and Trust of the Chinese-A Perspective on Interpersonal Relationship). 台湾: 远流出版事业股份有限责任公司, 8-12

杨中芳 (Yang Zhongfang)(2001b). 有关关系的人情构念化之综述 (A review of the conceptualization of interpersonal relationship and emotions). In: 中国人的人际关系、情感与 信任一几个人际交往的观点 (The Interpersonal Relationships, Affection and Trust of the Chinese-A Perspective on Interpersonal Relationship). 台湾: 远流出版事业股份有限责任公 司, 3-25

杨中芳(Yang Zhongfang) (2001c). 人际关系与人际情感的构念化 (The conceptualization of interpersonal relationships and emotions). In: 中国人的人际关系、情感与信任一几个人际交往 的观点 (The Interpersonal Relationships, Affection and Trust of the Chinese-A Perspective on Interpersonal Relationship). 台湾: 远流出版事业股份有限责任公司, 337-370

翟学伟 (Zhai Xuewei) (1993). 中国人际关系的特质——本土的概念及其模式 (The traits of Chinese interpersonal relationship-Indigenous concept and model). 社会学研究, (4): 74-83 翟学伟 (Zhai Xuewei) (2001). 中国人行动的逻辑 (The Logic in Chinese People's Behaviors). 北京: 社会科学文献出版社 